\title{
Multiparameter Optical Monitoring of Madeira Wine
}

\author{
http://dx.doi.org/10.3991/ijoe.v9iS8.3389 \\ V. Pereira ${ }^{1 *}$, J.C. Marques ${ }^{1}$, M.J. Carvalho ${ }^{1}$, M. Chen ${ }^{1}$, R. Sol ${ }^{1}$, C. Novo ${ }^{2}$, \\ L. Bilro $^{3}$, P. Antunes ${ }^{3}$, N. Alberto ${ }^{3}$, J.L. Pinto ${ }^{2}$ \\ ${ }^{1}$ University of Madeira, Funchal, Portugal \\ ${ }^{2}$ University of Aveiro, Aveiro, Portugal \\ ${ }^{3}$ Instituto de Telecomunicações, Aveiro, Portugal
}

\begin{abstract}
Madeira wine vinification process has been mostly empiric and requiring further studies. The present paper describes the existing pilot plant facility in Madeira University, with the installed controlled systems and safety devices. An advanced multi-parameter platform for real time monitoring and interactive data visualization is described and its potential use demonstrated.
\end{abstract}

Index Terms - online process control, physicochemical characterization, optical sensors, data visualization.

\section{INTRODUCTION}

Madeira wine is a well renowned fortified wine (17 $22 \%$ ), characterized essentially by its oxidized features acquired during its peculiar ageing. Since the $18^{\text {th }}$ century, Madeira wine ageing can be accelerated through a thermal processing denominated as estufagem, which consists in heating the wine usually at about $45{ }^{\circ} \mathrm{C}$ for at least 3 months. The oxidative ageing continues during years, in wood casks, before being sold. This thermal processing has been studied in the latest years to understand the transformations that occur during this step, in order to obtain valuable scientific information for the continuous improvement of the Madeira wine quality [1].

The production of a high-quality wine is usually performed based on quality control analyses that are timeconsuming and require sample destruction [2]. Thus, it makes sense to take advantage of the new technologies and develop new strategies that can facilitate this task, so that winemakers can readily gather, as much as possible, all the information about the whole process. To do so, the optical fiber sensing is the most adequate technology for this purpose, due to the possibility of on-line measurements. It also presents advantages over the electrical systems due to its immunity to electromagnetic interference, low degradation, excellent resolution and range, passive operation, small size and flexibility.

The present paper describes the facility installed for testing purposes, the off-line data obtained so far for the wine samples submitted to estufagem, the optical fiber platform and the interactive operation developed for the on-line data collection.

\section{PILOT SCALE FACILITY}

In Fig. 1 is depicted the pilot scale facility installed in the University of Madeira, where the wines were submitted to heating at $45 \pm 2{ }^{\circ} \mathrm{C}$ for 180 days. This facility is equipped with ten $200 \mathrm{~L}$ stainless steel tanks that simulate the industrial $20000 \mathrm{~L}$ tanks, with a heating system designed for independent control of temperature, by the circulation of preheated hot tap water through an internal circulating coil present in each tank. A safety control circuit is also implemented. The tanks have about $730 \mathrm{~mm}$ of height by $620 \mathrm{~mm}$ of width and are disposed in five parallel groups of two tanks placed in series, as showed by the scheme (Fig. 1). Moreover, the system allows an automatic operation during the heating period.

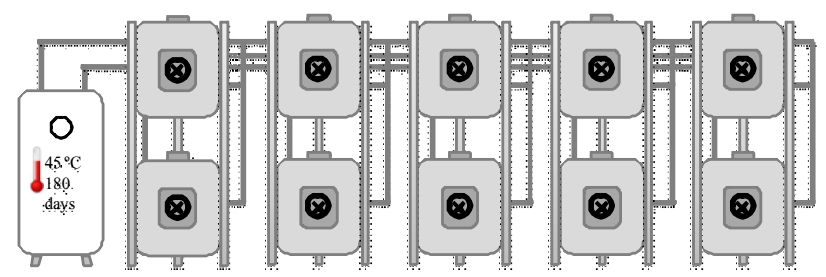

Figure 1. Scheme of the pilot scale facility used for the controlled heating of Madeira wines, installed in the University of Madeira.

\section{PHYSICOCHEMICAL CHARACTERIZATION}

Madeira wines made from traditional grape varieties (Malvasia, Boal, Verdelho, Sercial and Tinta Negra) followed the heating process in the previous pilot system. The wines were monthly analyzed through chromatographic and spectrophotometric (UV-VIS-IR) measurements.

From the obtained wine spectra several regions can be highlighted (Fig. 2), given that they can be correlated with important groups of compounds with relevance during the winemaking process that matter control. One of them, the $280 \mathrm{~nm}$ region is well correlated $\left(\mathrm{R}^{2}>0.9\right)$ with the presence of 5-hydroxymethylfurfural (HMF), as shown on Fig. 3.

The interest on HMF formation is closely related with food quality but also with a safety perspective, due to its potential toxic effects [3]. Since HMF development is related with high sugar levels associated to heating, estufagem together with the fact that some Madeira wine styles are very sweet, triggers interest to monitorize it, namely trough on-line control. Thus, the conditions of the heating step can be customized with the intention of maintain its characteristics without compromising the final amount of HMF and contributing to improve general quality [4]. 


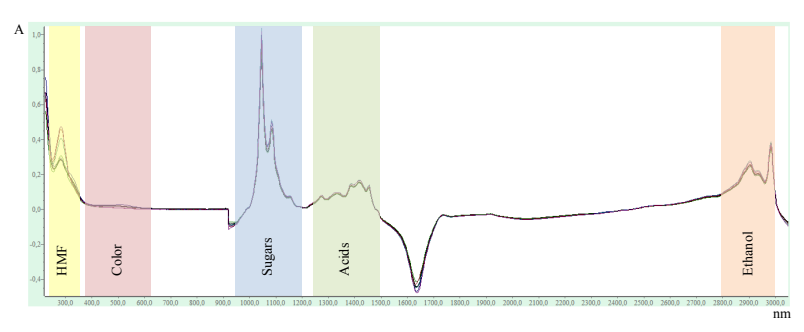

Figure 2. Typical UV-Vis-IR spectra of Tinta Negra sweet wines.

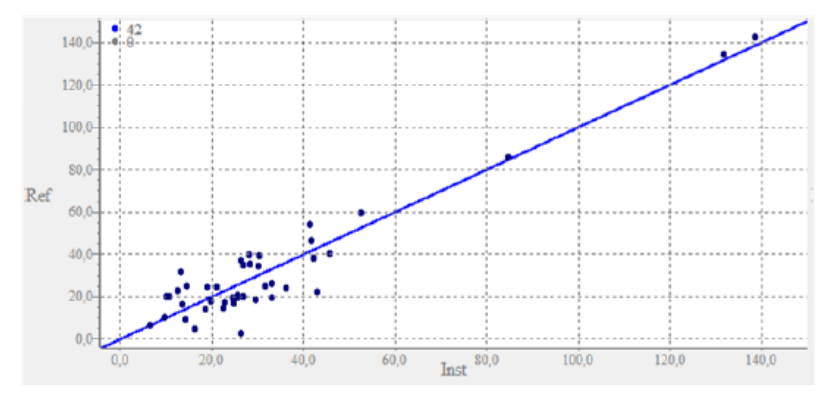

Figure 3. Correlation graph between $\mathrm{A}_{280}$ and HMF content present in Madeira wines

Other important region is the visible one, particularly the wavelengths at 420,520 and $620 \mathrm{~nm}$, which are related to wine color. Madeira wine has an intense color and as any other food, needs to be appellative to the consumers. Therefore there is the need to study the color development in Madeira wines while ageing, namely by estufagem. The most common method used in wineries to measure color is based on Glories chromatic parameters, in which several indexes $(\% \mathrm{Ye}, \% \mathrm{Re}, \% \mathrm{Bl}, \mathrm{CI}$ and To) are calculated based on absorbance measures at 420, 520 and $620 \mathrm{~nm}$.

Table I presents the absorbance values obtained for two Tinta Negra wines (sweet and dry) over 180 days of heating. In general, absorbance values tend to decrease during estufagem, implying that there is a loss of chromaticity during this step. Despite the absorbance at $420 \mathrm{~nm}$ (wavelength associated with yellow hue) decrease during heating this does not reveal the increase of the yellow hues, which is visually observed. Indeed, it is necessary to account all measured data to traduce the contribution of each hue. Thus, for developing the platform it is necessary to gather and work the obtained data in order to traduce this raw data into practical information for winemakers.

The other regions highlighted in Fig. 2 should be further explored, namely those related with sugars, acids and alcohol, which appear at higher wavelengths.

\section{Multi-Parameter Optical PlatForm}

The developed optical platform for the pilot scale facility is based on a multi-wavelength detection scheme with four measurements cells each dedicated to one selected wavelength and centered wavelengths at $470 \mathrm{~nm}, 530 \mathrm{~nm}$, $660 \mathrm{~nm}$ and $870 \mathrm{~nm}$ [5-7]. The sensor head is designed to be at a position that will always be submersed in the wine, considering that small samples are periodically removed from the tanks for physicochemical analysis. The data is acquired at $4 \mathrm{~Hz}$ with 10 bit resolution. Each data point acquired resulted from the average of three readings. An application in LabView ${ }^{\circledR}$ is used for Bluetooth communication control and storage. The sensor system, with interrogation and transmission system, is located on the top of the stainless steel tanks, as shown in Fig.4
TABLE I.

GLORIES PARAMETERS ( $\mathrm{A}_{420}, \mathrm{~A}_{520}, \mathrm{~A}_{620}, \%$ Ye, $\%$ RE AND \%BL) OF TINTA NEGRA SWEET AND DRY WINES, DURING 180 DAYS OF ESTUFAGEM.

\begin{tabular}{|c|c|c|c|c|c|c|c|c|c|}
\hline \multicolumn{10}{|c|}{ Tinta Negra Sweet } \\
\hline Days & $A_{420}$ & $S D^{a}$ & $\% Y e$ & $A_{520}$ & $S D^{a}$ & $\% R e$ & $A_{620}$ & $S D^{a}$ & $\% B l$ \\
\hline $\mathbf{0}$ & 1.205 & 0.059 & 44.417 & 1.302 & 0.064 & 48.003 & 0.206 & 0.015 & 7.580 \\
\hline 33 & 0.908 & 0.036 & 54.382 & 0.667 & 0.029 & 39.988 & 0.095 & 0.016 & 5.630 \\
\hline 62 & 0.922 & 0.008 & 61.433 & 0.505 & 0.006 & 33.655 & 0.074 & 0.003 & 4.912 \\
\hline 90 & 0.895 & 0.013 & 63.372 & 0.453 & 0.009 & 32.080 & 0.064 & 0.004 & 4.548 \\
\hline 120 & 0.901 & 0.007 & 65.523 & 0.418 & 0.004 & 30.435 & 0.055 & 0.002 & 4.042 \\
\hline 149 & 0.896 & 0.001 & 66.568 & 0.389 & 0.001 & 28.934 & 0.060 & 0.001 & 4.498 \\
\hline 180 & 0.867 & 0.011 & 69.708 & 0.333 & 0.009 & 26.775 & 0.044 & 0.007 & 3.517 \\
\hline \multicolumn{10}{|c|}{ Tinta Negra Dry } \\
\hline Days & $A_{420}$ & $S D^{a}$ & $\% Y e$ & $A_{520}$ & $S D^{a}$ & $\% R e$ & $A_{620}$ & $S D^{a}$ & $\% B l$ \\
\hline $\mathbf{0}$ & 0.405 & 0.014 & 58.375 & 0.239 & 0.014 & 34.448 & 0.051 & 0.017 & 7.177 \\
\hline 33 & 0.328 & 0.012 & 69.452 & 0.126 & 0.006 & 26.694 & 0.018 & 0.002 & 3.854 \\
\hline 62 & 0.415 & 0.003 & 73.972 & 0.132 & 0.002 & 23.572 & 0.014 & 0.001 & 2.456 \\
\hline 90 & 0.416 & 0.004 & 74.081 & 0.128 & 0.002 & 22.736 & 0.018 & 0.001 & 3.183 \\
\hline 120 & 0.398 & 0.009 & 77.620 & 0.108 & 0.006 & 21.003 & 0.007 & 0.004 & 1.376 \\
\hline 149 & 0.421 & 0.007 & 74.928 & 0.121 & 0.003 & 21.558 & 0.020 & 0.002 & 3.514 \\
\hline 180 & 0.380 & 0.007 & 83.407 & 0.084 & 0.004 & 18.296 & -0.008 & 0.002 & $1 . \overline{7} 703$ \\
\hline
\end{tabular}
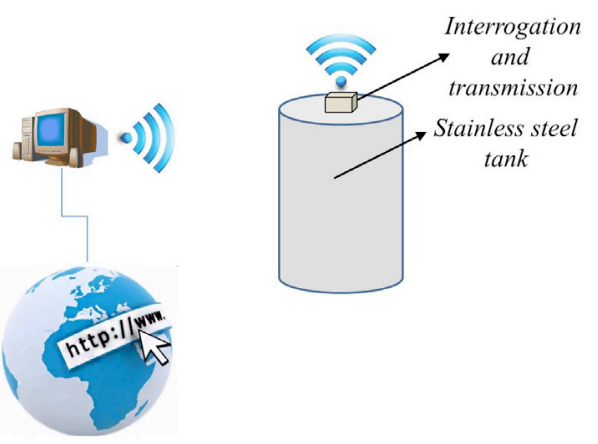

Figure 4. Schematic diagram of the system.

A silica fiber based temperature sensor is also included. It consists on a perforated stainless steel tube inside which there is an optical fiber with several multiplexed FBGs placed at different heights inside the wine tank. The stainless tube is perforated, in order to allow the easy access of the wine to the inside of the tube. Temperature sensitivities of approximately $13 \mathrm{pm} /{ }^{\circ} \mathrm{C}$ can be obtained.

\section{DATA VisUALIZATION}

The monitoring platform includes an interactive data visualization tool. Robinson and Shapcott [8] argued that information visualization should be used not only to present final results, but also to play an important role during the entire process. Therefore, we create an interactive visualization tool for scientists and wine producers to engage the process in order to facilitate the mining process. Different ways of visualization techniques were explored and a website is used as a discovery tool and a medium to encourage discussion among users. Typical current readings of temperature and historical data are shown in Fig.5. 


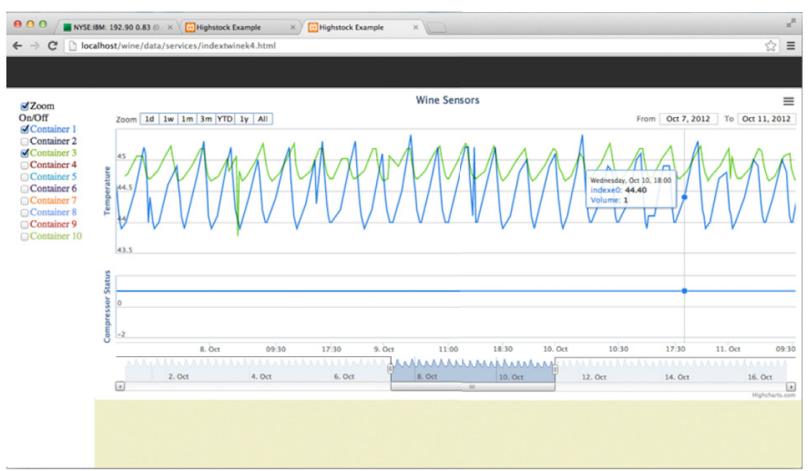

Figure 5. A screen capture of the visualization web showing data collected from temperature sensors.

The aim is to increase the awareness of the heating process with a flexible visualization tool as well as to identify any abnormal conditions. Therefore, the interface was designed to allow users to easily navigate and change the time scale. A popup tip shows the reading of the sensor when users check a particular point of the chart. The subsequent version of the interface will incorporate all the information of the optical platform sensing.

\section{CONCLUSIONS AND FUTURE DEVELOPMENTS}

A platform for multi-parameter monitoring of Madeira wine is presented. It includes the physicochemical characterization, the optical sensor and the related visualization techniques which can allow online data collection and immediate interaction with the process. The foreseen evolution of the pilot scale facility is expected to have a significant impact on the scientific understanding of the kinetics of ageing aroma formation and to provide new insights for the industrial vinification and ageing process followed by Madeira wines.

Future developments will be focused on the implementation of an optical sensing network, measuring different parameters such as refractive index, color, and temperature, among others, positioned at the wine steel tanks where the estufagem is taking place, and using optical communication methods transmitting the sensors signal to another location where a central system can process and filter the parameters of interest to the responsible personnel. Other relevant parameters may also be considered.

The system will comprise the optical fiber network and the central analyses software, including a full automated control with alarm sending (via e-mail or sms) in the case of hazard, such as temperature increase during a system failure. Optical fiber sensors are also expected to be developed and/or the optimization of previously reported solutions.

The present and future systems are expected to contribute significantly to a full automated and controlled industrial wine process, aiming to control the quality of produced wine in a cost effective and industrialized way.

\section{ACKNOWLEDGMENT}

The authors acknowledge ADI - Agência da Inovação and FEDER (Project IMPACT), FCT - Fundação para a Ciência e Tecnologia for the financial support through PEst-C/CTM/LA0025/2011 and project PTDC/EQUEPR/114685/2009 and Madeira Wine Company for the supply of the wines under study. They also gratefully acknowledge the financial support through the FCT Postdoctoral fellowships SFRH/BPD/78205/2011, SFRH/BPD/78141/2011 and SFRH/BPD/76735/2011.

\section{REFERENCES}

[1] Pereira, V., "Effect of the estufagem process on the chemical constituents of Madeira wines".PhD Thesis, Madeira University, 2011

[2] Gowen A.A., O’Donnell C.P., Cullen P. J., Downey G., Frias J.M., "Hiperspectral imaging - an emerging process analytical tool for food quality and safety control", Trends Food Sci. Technol. vol 18, pp. 590-598, 2007http://dx.doi.org/10.1016/j.tifs. 2007.06.001

[3] Monien B.H., Frank H., Seidel A., Glatt H., "Conversion of the common food constituent 5-hydroxymethylfurfural into a mutagenic and carcinogenic sulfuric acid ester in the mouse in vivo", Chem. Res. Toxicol., vol 22, pp. 1123-1128, 2009. http://dx.doi.org/10.1021/tx9000623

[4] Pereira V., Albuquerque F.M., Ferreira A.C., Cacho J., Marques J.C., "Evolution of 5-hydroxymethylfurfural (HMF) and furfural (F) in fortified wines submitted to overheating conditions", Food Res. Int., vol 44, pp. 71-76, 2011. http://dx.doi.org/10.1016/ j.foodres.2010.11.011

[5] Bilro L., Prats S. , Pinto J. L., Keizer J.J. and Nogueira R. N., "Design and performance assessment of a plastic optical fibre based sensor for measuring water turbidity ", Meas. Sci. and Tech vol 21, pp. 107001-4, 2010 http://dx.doi.org/10.1088/09570233/21/10/107001

[6] Bilro L, Prats S, Pinto J.L., Keizer J.J. and Nogueira R. N., "Turbidity sensor for determination of concentration, ash presence and particle diameter of sediment suspensions", Proc. SPIE, vol. 7753 , pp. $775356-775356-4,2011$

[7] Kuang, K.S.C., Quek, S.T. e Maalej, M., "Assessment of an extrinsic polymer-based optical fibre sensor for structural health monitoring ", Meas. Sci. and Tech, vol 15, pp. 2133-2141, 2005 http://dx.doi.org/10.1088/0957-0233/15/10/024

[8] Robinson, N., Shapcott, M., "Data mining information visualisation-beyond charts and graphs". In Information Visualisation, Proceedings of Sixth International Conference, IEEE, pp. 577-583), 2002

\section{AUTHORS}

V. Pereira is with Centre of Exact Sciences and Engineering, University of Madeira, Funchal, Portugal. He is corresponding author of this paper: vpereira@uma.pt.

J.C. Marques and M. J. Carvalho are with Centre of Exact Sciences and Engineering, University of Madeira, Funchal, Portugal.

M. Chen and R. Sol are with the Madeira Interactive Technologies Institute, University of Madeira, Funchal, Portugal.

C. Novo is with the I3N \& Physics Department, University of Aveiro, Aveiro, Portugal.

L. Bilro, P. Antunes, and N. Alberto are with the Instituto de Telecomunicações, Aveiro, Portugal.

J. L. Pinto is with the I3N \& Physics Department, University of Aveiro, Aveiro, Portugal.

This work has been financially supported by ADI - Agência da Inovação and FEDER (Project IMPACT), FCT - Fundação para a Ciência e Tecnologia through PEst-C/CTM/LA0025/2011 and project PTDC/EQU-EPR/114685/2009 and through the FCT Postdoctoral fellowships SFRH/BPD/78205/2011, SFRH/BPD/78141/2011 and SFRH/BPD/76735/2011. This article is an extended and modified version of a paper presented at the International Conference exp.at'13, held 18-20 September 2013, in Coimbra, Portugal. Submitted 18 November 2013. Published as re-submitted by the authors 04 December 2013. 